\title{
Recovery of Zinc from Treatment of Spent Acid Solutions from the Pickling Stage of Galvanizing Plants
}

\author{
Svetlana B. Zueva ${ }^{1,2} \odot$, Francesco Ferella ${ }^{1, *(0)}$, Valentina Innocenzi ${ }^{1}$, Ida De Michelis ${ }^{1}$, Valentina Corradini ${ }^{1}$, \\ Nicolò M. Ippolito ${ }^{1}$ and Francesco Vegliò ${ }^{1}$ (D) \\ 1 Department of Industrial and Information Engineering and Economics, University of L'Aquila, \\ 67100 L'Aquila, Italy; svetlana.zueva@univaq.it (S.B.Z.); valentina.innocenzi1@univaq.it (V.I.); \\ ida.demichelis@univaq.it (I.D.M.); valentina.corradini@univaq.it (V.C.); \\ nicolomaria.ippolito@univaq.it (N.M.I.); francesco.veglio@univaq.it (F.V.) \\ 2 Department of Chemical Engineering, Voronezh State University of Engineering, 394036 Voronezh, Russia \\ * Correspondence: francesco.ferella@univaq.it; Tel.: +39-0862-434238
}

check for

updates

Citation: Zueva, S.B.; Ferella, F.;

Innocenzi, V.; De Michelis, I.;

Corradini, V.; Ippolito, N.M.; Vegliò, F.

Recovery of Zinc from Treatment of

Spent Acid Solutions from the

Pickling Stage of Galvanizing Plants.

Sustainability 2021, 13, 407. https://

doi.org/10.3390/su13010407

Received: 2 December 2020

Accepted: 2 January 2021

Published: 5 January 2021

Publisher's Note: MDPI stays neutral with regard to jurisdictional clai$\mathrm{ms}$ in published maps and institutional affiliations.

Copyright: (C) 2021 by the authors. Licensee MDPI, Basel, Switzerland. This article is an open access article distributed under the terms and conditions of the Creative Commons Attribution (CC BY) license (https:// creativecommons.org/licenses/by/ $4.0 /)$.

\begin{abstract}
Typical methods for the treatment of waste pickling solutions include precipitation by alkaline reagents, most commonly calcium hydroxide. As a result, large volumes of galvanic sludge form, containing iron, calcium, sulphates, and a relatively small quantity of zinc $(<20 \%)$, making $\mathrm{Zn}$ recovery not profitable. In summary, state-of-the-art Zn galvanization processes entail the loss of valuable metals and the irrational and expensive handling of spent pickling solutions (SPSs). The resulting conclusion is that there is room for a significant improvement in the way SPSs are treated, with the double goal of enhancing $\mathrm{Zn}$ galvanization methods' economic viability and achieving a lesser impact on the environment's processes. The experimental results show that it is possible to use SPS as a coagulant to treat the process wastewaters, kept separated, and added with sodium hydroxide. The results in obtaining precipitates with $\mathrm{Zn}$ contents higher than $40 \%$, increasing the added advantage of making $\mathrm{Zn}$ recovery profitable. The results show the possibility of using SPS as a coagulant in the process of physical-chemical wastewater treatment and sodium hydroxide to obtain a precipitate with a zinc content of more than $40 \%$.
\end{abstract}

Keywords: wastewater; spent pickling solution; precipitation; zinc; hydrochloric acid

\section{Introduction}

Applying a zinc coating to increase the corrosion resistance of steel is called "galvanization", a neologism created in honor of the Italian scientist Luigi Galvani, the discoverer of bio-electricity. Many industrial methods are in use and two of the most common ones, hotdip and in-line processing, do not entail using an electric current. In contrast, electroplating and several other ones do, such as powder coating, painting, and sherardizing [1,2].

Most methods have in common the initial steps, which aim to prepare the steel surface for bonding with Zinc. The primary initial steps are as follows: (1) Degreasing, (2) pickling with hydrochloric acid in order to remove iron oxides such as rust or scale, and (3) rinsing with water and fluxing to chemically activate the steel surface and enhance the reaction with zinc [3].

Galvanizing plants produce effluents that constitute a special hazardous waste because of the high concentration of metals and acids. Pickling solutions contain up to $70 \%$ of contaminants and are periodically dumped into rinsing water, typically in one go, which leads to possible violations of the legal purification standards as well as the loss of valuable components. Furthermore, another pejorative factor is the reduced length of the pickling stage, which ordinarily is carried out in the industry in order to contain treatment time. The resistance of steel to corrosion is obtained with a number of industrial processes based on $\mathrm{Zn}$ galvanization. However, all these methods bear a relatively high price tag due to the cost of zinc plates and electrolytes as well as the formation of hazardous wastewaters 
containing metals and acids. Wastewaters from $\mathrm{Zn}$ galvanization may be grouped into two main types: A mix of rinse water (MRW) and spent pickling solutions (SPS). Ordinarily, these waters are mixed and sent for treatment within economically viable limits. As a result, SPS are hazardous and wasteful.

From all of the above, it is evident that the regeneration of spent pickling solutions is highly desirable for environmental protection and the economic viability of industrial processes. [4]. Our group was chartered with this task by an electroplating plant located in Chieti, central Italy, which specialized in the galvanization of automotive components. In electroplating, two types of effluents usually form: rinsing water and concentrated pickling solutions. This research work led to substantial improvement under both the environmental and financial profile and promoted the galvanizing industry's enhanced sustainability. Our method's main novelty was the re-utilization of part of the effluents as a coagulant in the purification process.

\subsection{Overview of Current Methods}

As said above, the treatment of spent pickling solutions (SPS) poses two typical problems, as follows. First comes the recycling of hydrochloric acid and then, secondly, the recovery of valuable metals. Various SPS regeneration methods are currently in use in the industry, depending on the concentration of the chemicals present in the water. However, most of them only recover hydrochloric acid, leaving zinc and iron in a concentrated sludge that is disposed of without further treatment. To size up the extent of this waste, SPSs (spent pickling solutions) may contain $5-60 \mathrm{~g} / \mathrm{L}$ of Zn. Considering that the EU produces $300,000 \mathrm{~m}^{3}$ /year of this type of effluents, simple calculations lead to the result that $\mathrm{Zn}$ waste in the EU amounts to about $1500-18,000 \mathrm{t} /$ year. In other words, quite a sizeable waste.

Worldwide, $\mathrm{HCl}^{\prime}$ s recovery with the pyrometallurgical method is obtained on an industrial scale in about 80 plants [4]. Disadvantages are as follows: (1) Environment unfriendliness, (2) high energy consumption, and (3) the impossibility to process solutions containing more than $0.5 \mathrm{~g} / \mathrm{L}$ of zinc(II).

Some membrane techniques were proposed to recover $\mathrm{HCl}$, among them, diffusion dialysis $[5,6]$ and membrane distillation $[7,8]$. Another way to recycle the acid is through the electrodialysis of spent pickling solutions $[9,10]$. However, all these methods are affected by the formation of undesired by-products (e.g., chlorine gas).

Separation of Iron and Zinc from SPSs can be obtained through chemical processes such as ion exchange, solvent extraction, and chemical precipitation.

Ion exchange needs large volumes of resin and, consequently, high investment costs. Furthermore, resin regeneration would produce large volumes of diluted zinc solutions, requiring further treatment and disposal. The separation of Zn from SPSs may also be affected through solvent extraction [11,12], membrane-based solvent extraction [13], and solvent extraction followed by precipitation-stripping [14]. Solvent extraction methods make it possible to separate $\mathrm{FeCl}_{3}$ and $\mathrm{ZnCl}_{2}$ from $\mathrm{HCl}$, but as a rule, they have a high cost and result in a solvent loss to aqueous effluents.

Another chemical process to recover metals is precipitation with oxalic acid $[15,16]$. The use of oxalic acid as a reagent results in good selectivity and efficient leaching. The process is energy-efficient but has the negative of requiring a stoichiometric amount of acid in excess of $300 \%$.

Finally, a widespread and straightforward treatment is precipitation-filtration with lime. Inorganic coagulants (for example, iron chloride) or polyelectrolytes are often added to the wastewater to reduce the volume and water content of the precipitate in the last stage of sedimentation. In conclusion, reagent methods are characterized by the formation of large amounts of sludge containing toxic compounds of heavy metals. The disposal of sludge poses yet new problems, as it requires chemical treatments and appropriate landfills.

Methods to recycle galvanic sludge include the incorporation in cement production [17], formulation of inorganic pigments [18], in addition to ceramic materials [19], 
and is used in asphalt emulsions [20,21]. However, in recent times, the presence of valuable metals has increasingly fueled the search for methods to recover them.

\subsection{Novelty of this Research}

The foremost obstacle met in recovering zinc from galvanic waste is the economic viability of the process. Data from the industry indicate that at the present state of the art, zinc recovery is cost-effective only if its content in solid waste is higher than $40 \% \mathrm{w} / \mathrm{w}$, which is far more than the concentration that typically occurs in waste sludge from current galvanization methods.

The obvious method to recover zinc from galvanization sludge is precipitation obtained using calcium hydroxide as a coagulant. However, it is economically not viable because of the low concentration of zinc in the waste.

Our research devised a method to increase zinc concentration in the sludge above the mentioned $40 \%$ threshold by utilizing as a precipitating agent sodium hydroxide instead of calcium hydroxide and the SPS itself coming from the process as a coagulant.

\section{Materials and Methods}

\subsection{Chemicals and Solutions}

Experiments were carried out on four samples of wastewater collected from a galvanizing plant specialized in automotive components, located in Italy. These samples were collected from the pickling and washing steps. One sample came from one SPS, whereas the remaining three were taken from the MRW over two months to cover all possible variations in the spectrum of chemicals present in the water. Table 1 below shows the chemical composition of the said samples.

Table 1. Characteristics of the wastewater samples.

\begin{tabular}{|c|c|c|c|c|c|c|c|}
\hline & \multirow{2}{*}{$\mathrm{pH}$} & \multirow{2}{*}{$\mathrm{Zn}, \mathrm{g} / \mathrm{L}$} & \multirow{2}{*}{$\mathrm{Fe}, \mathrm{g} / \mathrm{L}$} & \multirow{2}{*}{$\mathrm{Cl}, \mathrm{g} / \mathrm{L}$} & \multirow{2}{*}{$\mathrm{SO}_{4}, \mathrm{~g} / \mathrm{L}$} & \multicolumn{2}{|c|}{ Surfactants, mg/L } \\
\hline & & & & & & Anionic & Cationic \\
\hline \multicolumn{8}{|c|}{ Spent Pickling Solutions (SPS) } \\
\hline SPS & 0.4 & 33.27 & 14.96 & 321.00 & 0.169 & 25.2 & 0.31 \\
\hline \multicolumn{8}{|c|}{ Mix of Rinse Waters (MRW) } \\
\hline MRW-1_15/02/2019 & 6.2 & 4.87 & 1.48 & 1.01 & 0.49 & 4.1 & 7.3 \\
\hline MRW-2_15/03/2019 & 5.4 & 8.54 & 5.94 & 1.13 & 0.56 & 1.14 & 0.142 \\
\hline MRW-3_15/04/2019 & 3.5 & 6.72 & 3.95 & 1.38 & 0.64 & 1.10 & 0.095 \\
\hline
\end{tabular}

Hydrated lime (calcium hydroxide) $10 \%(\mathrm{w} / \mathrm{v})$, sodium hydroxide $40 \%(\mathrm{w} / \mathrm{v})$, and $\mathrm{FeCl}_{3}$ $(40 \% \mathrm{v} / \mathrm{v})$ were used for the precipitation tests.

\subsection{Experimental Procedures}

The experiments were carried out to define the combination of reactants that would result in the maximum cleaning effect and the minimum sludge formation to achieve $\mathrm{Zn}$ content in the sludge of at least $40 \%(\mathrm{w} / \mathrm{w})$. The study consisted of four sets of experiments (Table 2). As an alternative to lime, to increase the mass content in the resulting zinc precipitate, the deposition process was carried out with sodium hydroxide. Most importantly, the feasibility of replacing iron chloride with the SPS itself was studied.

Table 2. Reagents and relevant combinations studied in the precipitation tests.

\begin{tabular}{ccccc}
\hline No. & Lime & $\mathrm{NaOH}$ & $\mathrm{FeCl}_{3}$ & SPS \\
\hline 1 & + & - & + & - \\
2 & - & + & + & - \\
3 & + & - & - & + \\
4 & - & + & - & + \\
\hline
\end{tabular}


The precipitation of zinc hydroxide occurs in the $\mathrm{pH}$ range $\mathrm{pH}$ 6.4-8.0 with its subsequent dissolution with an increase in $\mathrm{pH}$ above 10 [22]. The reagents were gradually added under constant stirring during the precipitation stage until reaching $\mathrm{pH}$ between 9.5-10. The mixture was then further stirred for an additional two hours in order to ensure precipitation equilibrium. After that, a coagulant was added (either $\mathrm{FeCl}_{3}$ or SPS) and stirred at approximately $100 \mathrm{rpm}$ for $1 \mathrm{~min}$. The stirring speed was then reduced to $50 \mathrm{rpm}$ and kept at that level for 15 to $20 \mathrm{~min}$.

When the stirring was over, the final $\mathrm{pH}$ value was measured, and the precipitate was separated through vacuum filtration. Then it was washed three times with demineralized water and finally dried at a temperature of $105^{\circ} \mathrm{C}$.

A quantitative analysis was carried out after the acid attack to evaluate the content of $\mathrm{Zn}, \mathrm{Fe}$, and $\mathrm{Ca}$ in the precipitate. The acid attack was performed in a $25 \mathrm{~mL}$ closed flask as follows: Around $0.5 \mathrm{~g}$ of initial materials were dissolved with 1:3 of nitric and hydrochloric acid at $90{ }^{\circ} \mathrm{C}$.

\subsection{Methods of Analysis}

An X-ray fluorescence XRF spectrophotometer (Spectro XEPOS 2000) and a fast sequential atomic absorption spectrometer (Varian AA240FS) were used to perform the chemical analyses of wastewater and wastewater precipitate.

Chlorides and COD were measured with Dr. Lange's kit, as well as the cuvette-test LCK 153 and LCK 114A.

Total suspended solids (TSS) were measured using a modified version of the Standard Method 2540 for solids determinations in the water and wastewater industry [13].

\section{Results and Discussion}

With varying concentrations of anionic and cationic surfactants, four different treatments were carried out on each MRW sample. Table 3 shows the composition of wastewater MRW-1 after zinc precipitation with various reagents. As shown, $\mathrm{Zn}$ 's concentration is significantly lower in the wastewater sample treated with $\mathrm{NaOH}$ and SPS than lime and $\mathrm{FeCl}_{3}$.

Table 3. Composition of sample MRW-1 after treatment.

\begin{tabular}{|c|c|c|c|c|c|c|c|c|c|c|c|c|}
\hline \multirow{2}{*}{ No. } & \multicolumn{4}{|c|}{ Reagent Consumption, g/L } & \multirow{2}{*}{$\mathrm{pH}$} & \multirow{2}{*}{$\begin{array}{c}\mathrm{Zn}, \\
\mathrm{mg} / \mathrm{L}\end{array}$} & \multirow{2}{*}{$\begin{array}{c}\mathrm{Fe}, \\
\mathrm{mg} / \mathrm{L}\end{array}$} & \multirow{2}{*}{$\begin{array}{c}\mathrm{Cl}, \\
\mathrm{mg} / \mathrm{L}\end{array}$} & \multirow{2}{*}{$\begin{array}{l}\mathrm{SO}_{4}, \\
\mathrm{mg} / \mathrm{L}\end{array}$} & \multirow{2}{*}{$\begin{array}{l}\text { TSS, } \\
\mathrm{mg} / \mathrm{L}\end{array}$} & \multicolumn{2}{|c|}{ Surfactants, mg/L } \\
\hline & Lime & $\mathrm{NaOH}$ & $\mathrm{FeCl}_{3}$ & SPS & & & & & & & Anionic & Cationic \\
\hline 1 & 8.70 & - & 0.2 & - & 9.8 & 0.72 & 0.02 & 854 & 250 & 14,390 & 1.10 & 0.16 \\
\hline 2 & - & 9.45 & 0.2 & - & 9.8 & 0.78 & 0.03 & 854 & 240 & 10,595 & 1.16 & 0.24 \\
\hline 3 & 8.62 & - & - & 2 & 9.5 & 0.76 & 0.05 & 1120 & 305 & 14,310 & 1.18 & 0.25 \\
\hline 4 & - & 9.25 & - & 2 & 9.5 & 0.68 & 0.04 & 1120 & 310 & 10,580 & 1.10 & 0.29 \\
\hline
\end{tabular}

Experiments showed that a spent pickling solution (SPS) could have a good coagulating effect. This can be explained by fact that in an acidic chloride solution such an SPS, $\mathrm{Fe}$ (II), $\mathrm{Fe}(\mathrm{III})$, and $\mathrm{Zn}$ (II) exist as a series of chloride complexes: $\mathrm{ZnCl}_{2}, \mathrm{Fe}^{2+},[\mathrm{FeCl}]^{+}$, $[\mathrm{FeCl}]^{2+},\left[\mathrm{FeCl}_{2}\right]^{+}$, and $\mathrm{FeCl}_{3}[3]$. Therefore an SPS can have the properties of a coagulant consisting of a mix of ferric and zinc chloride. The samples' filtration rate after the addition of $\mathrm{FeCl}_{3}$ and SPS was the same. Furthermore, as shown in Figure 1, the replacement of lime and iron chloride with sodium hydroxide and SPS increases the zinc content in the sludge from $33.3 \%$ to $46.0 \%$. 


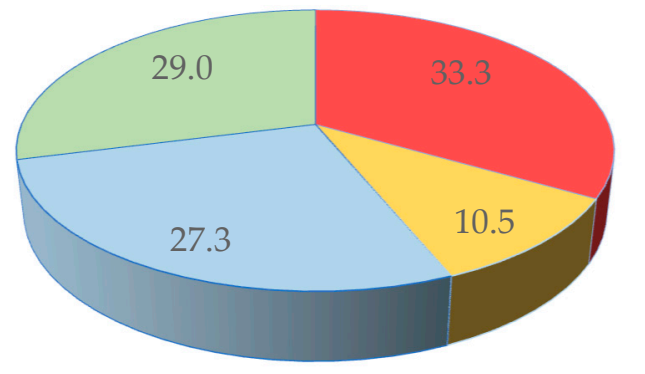

Zn $\square$ Fe $\square$ Ca $\square$ Other

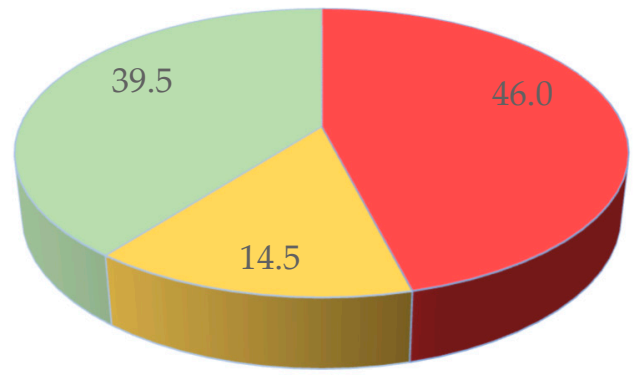

(b)

Figure 1. Composition ( $\% \mathrm{w} / \mathrm{w})$ of sediments after physico-chemical treatment of MRW-1 sample with: (a) Lime and $\mathrm{FeCl}_{3}$ and, (b) $\mathrm{NaOH}$ and SPS.

The replacement of calcium hydroxide with sodium hydroxide resulted in reducing the precipitate weight from $15.9 \mathrm{t} / \mathrm{m}^{3}$ to $10.4 \mathrm{t} / \mathrm{m}^{3}$.

Similar results were obtained experimenting on other samples (MRW-2 and MRW-3).

In all three studied wastewater samples, after precipitation with sodium hydroxide with SPS, the effect of zinc removal was at least $99.5 \%$, and the residual $\mathrm{Zn}$ and Fe concentrations were below the limit. According to the Italian limits of emission in the sewers, the permissible content of $\mathrm{Zn}$ is $1 \mathrm{mg} / \mathrm{L}$ and $\mathrm{Fe}$ is $4 \mathrm{mg} / \mathrm{L}$, discharged into the sewage network [23].

The results in Table 3 and Figure 1 show that precipitation with $\mathrm{NaOH}$ and SPS was the best compared among the precipitation methods in terms of the rate of $\mathrm{Zn}$ removal and its content in the sludge.

The effect of process time on zinc removal for the two different treatments (n. 1 and n. 4) is shown in Figure 2. As shown from the results of the experiment, $\mathrm{Zn}$ is completely precipitated within $2 \mathrm{~h}$ after reaching the desired $\mathrm{pH}=9.5$ (treatment $n .1$ ). In the case of precipitation with $\mathrm{NaOH}$ and SPS (treatment n.4), $1 \mathrm{~h}$ was enough to reach the maximum zinc removal.

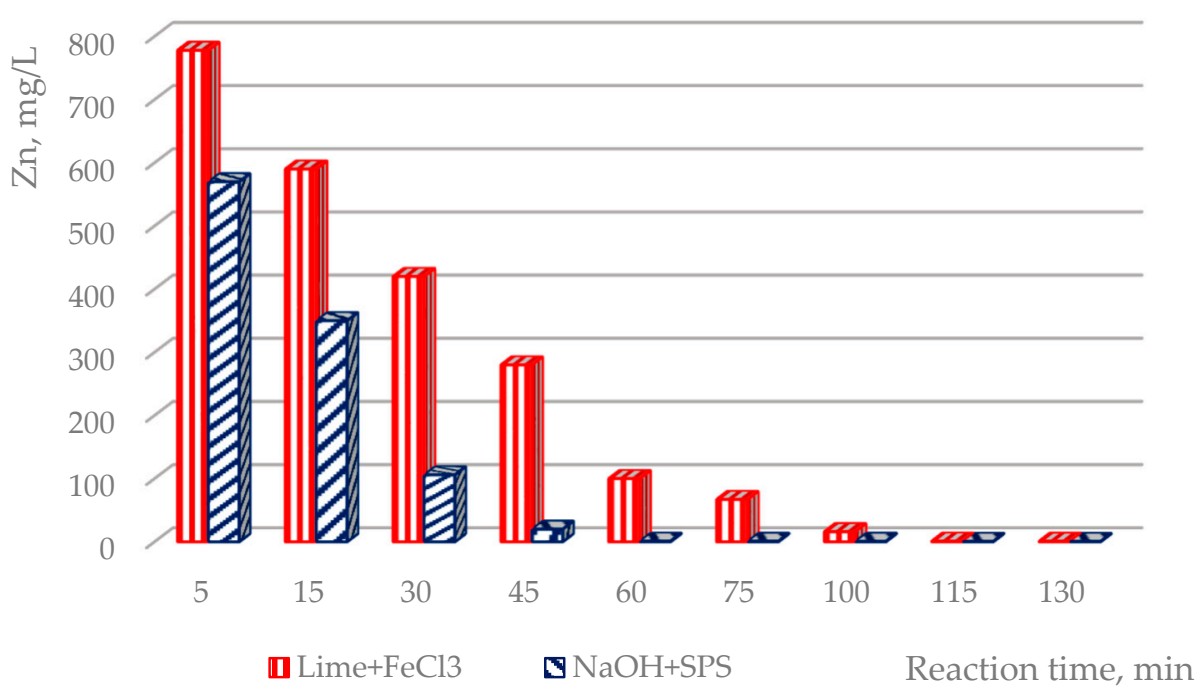

Figure 2. Concentration of $\mathrm{Zn}$ in the MRW-1 as a function of reaction time after reaching $\mathrm{pH} 9.5$.

Replacing calcium hydroxide with sodium hydroxide and setting up the cleaning process so that the acid waste, rather than being mixed with washings, is added at the end of the treatment as a coagulant in the place of iron chloride results in saving on iron chloride, which is already of some economic benefit. The cost of $1 \mathrm{~kg}$ of iron chloride, 
according to 2019 data, was 0.29 Euros. The plant consumption per year was 14.1 tons. Thus, replacing the coagulant with production waste will result in a saving of some 4000 Euros.

Nevertheless, the real gain stems from replacing calcium hydroxide with iron hydroxide, which will reduce the precipitate volume by a quarter and increase the zinc content by 1.4 times. In 2019, the company sent to an authorized disposal site 374.8 tons of sludge and paid 140,000 Euros for the disposal treatment. The increase in zinc content resulting from the above-said replacement of calcium hydroxide with sodium hydroxide will change the sludge's nature, turning it from hazardous waste class (F019) into a by-product suitable for subsequent zinc recovery, thus eliminating the cost of the disposal mentioned above. In other words, an annual saving of about 140,000 Euros can be obtained by replacing the coagulant previously used $\left(\mathrm{FeCl}_{3}\right)$ with waste from the cleaning stage and by recycling the sludge instead of sending it to an expensive disposal site.

In conclusion, considerable savings on the process cost can be achieved by keeping the acid waste resulting from the cleaning stage separate from the washings and then adding it as a coagulant at the end of the treatment, instead of the previously used iron chloride.

The flowchart and the relative mass balance for MRW-1 treatment are shown in the following Figure 3 . The process consists of a precipitation step with sodium hydroxide for $1 \mathrm{~h}$, followed by coagulation with SPS and further filtration to separate the precipitate from the liquid. The solid can be dried and then sold for Zn recovery, while the treated water could be sent to $\mathrm{Cl}$ recovery.

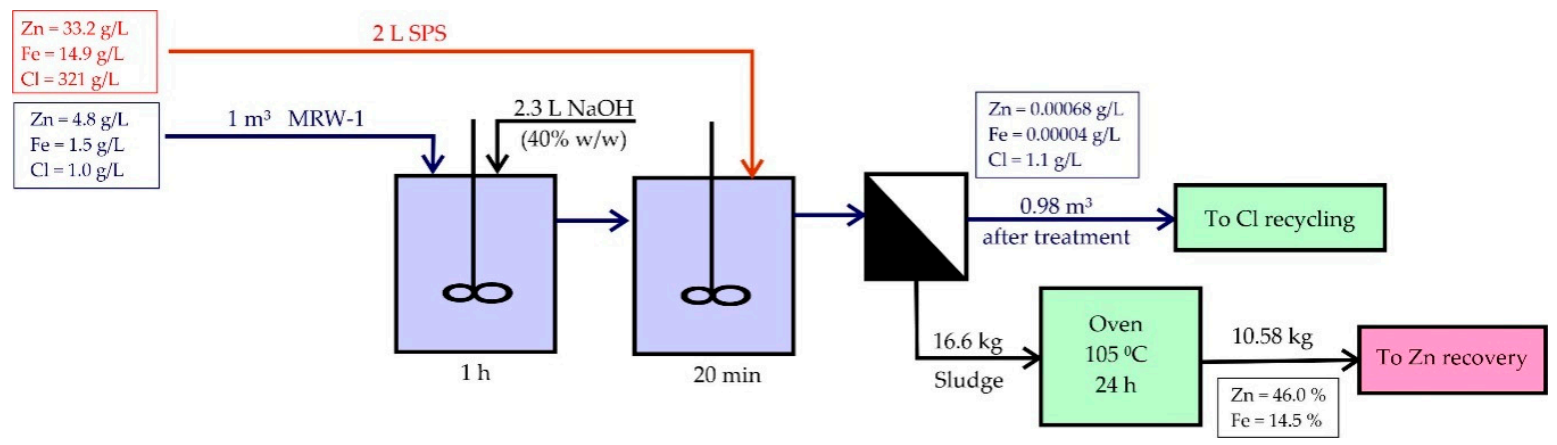

Figure 3. Flow-chart of the process (MRW-1 sample).

According to the mass balance, SPS consumption to treat $10 \mathrm{~m}^{3} / \mathrm{h}$ of MRW- 1 is $20 \mathrm{~L} / \mathrm{h}$. Considering that up to $600 \mathrm{~L}$ of SPS per day is formed at the enterprise (max $25 \mathrm{~L} / \mathrm{h}$ ), the proposed purification scheme allows the entire SPS to be processed as a coagulant.

\section{Conclusions}

The present paper deals with the treatment of an acid spent solution to recover zinc. These waste solutions from the galvanizing industry's pickling stage are usually treated by precipitation, but uncontrolled parameters lead to the production of a huge amount of sludge to dispose of. In this study, a precipitation process was optimized, leading to a zinc precipitate that could be reused as secondary raw material instead of being disposed of. This results in a double economic benefit for the galvanizing industry. In particular, this research led to the following findings:

(1) An increase of the sludge's zinc content by 1.4 times was obtained by replacing the commonly used treatment with lime and $\mathrm{FeCl}_{3}$ with the introduction of $\mathrm{NaOH}$ and SPS water. This increase in Zn content made the recovery of zinc cost-effective. In addition, replacing lime with soda allows one to reduce by a quarter the volume of the resulting sediment and the duration of the process by twice;

(2) The residual concentration of $\mathrm{Zn}$ and Fe in the wastewater resulting from the proposed process was below the admissible legal limits; 
(3) The new treatment resulted in annual savings of about 140,000 Euros because the plant would not have to bear, thenceforward, the cost of the legal disposal of the sludge;

(4) The results of this work will certainly guarantee better sustainability of the galvanizing industry.

Author Contributions: Conceptualization, F.V.; methodology, S.B.Z.; validation, V.I.; investigation, S.B.Z.; data curation, N.M.I.; writing — original draft preparation, S.B.Z.; analyses: V.C.; writingreview and editing, F.F.; visualization, I.D.M.; supervision, I.D.M., F.V. All authors have read and agreed to the published version of the manuscript.

Funding: This research did not receive any specific grant from funding agencies in the public, commercial, or not-for-profit sector.

Institutional Review Board Statement: Not applicable.

Informed Consent Statement: Not applicable.

Data Availability Statement: Data sharing not applicable.

Acknowledgments: The authors are very grateful to Fabiola Ferrante and Marcello Centofanti for their helpful collaboration given for the XRF and AAS analyses.

Conflicts of Interest: The authors declare no conflict of interest.

\section{References}

1. Pirošková, J.; Trpcevská, J.; Hluchánová, B.; Laubertová, M. Flux skimmings originated during hot-dip galvanizing process and its hydrometallurgical processing. Acta Metall. Slovaca 2012, 18, 34-39.

2. Bright, M.A.; Deem, N.J.; Fryatt, J. The advantages of recycling metallic zinc from the processing wastes of industrial molten zinc applications. In 2007 TMS Annual Meeting E Exhibition; The Minerals, Metals and Materials Society: Orlando, FL, USA, 2007; pp. 101-109.

3. Pietrelli, L.; Ferro, S.; Vocciante, M. Raw materials recovery from spent hydrochloric acid-based galvanizing. Chem. Eng. J. 2018, 341, 539-546.

4. Regel-Rosocka, M.; Cieszycska, A.; Wioeniewski, M. Methods of regeneration of spent pickling solutions from steel treatment Plants. Pol. J. Chem. Technol. 2007, 9, 42-45.

5. Naliena, M.; Faieza, A.A.; Rosnah Binti, M.Y. Minimization of spent acid waste from galvanizing plant in Malaysia. Glob. J. Res. Eng. 2013, 13, 14-24.

6. Machado, R.M.; Gameiro, M.L.F.; Rodrigues, J.M.A.; Ismael, M.R.C.; Reis, T.A.; Carvalho, J.M.R. Recovery of hydrochloric acid from galvanizing industrial effluents. Sep. Sci. Tech. 2017, 52, 1333-1340.

7. Regel-Rosocka, M.A. review on methods of regeneration of spent pickling solutions from steel processing. J. Hazard. Mater. 2010, 177, 57-69.

8. Devi, A.; Singhal, A.; Gupta, R. A study on treatment methods of spent pickling liquor generated by pickling process of steel. Clean Techn. Environ. Policy 2014, 16, 1515-1527.

9. Gurreri, L.; Tamburini, A.; Cipollina, A.; Micale, G. Electrodialysis applications in wastewater treatment for environmental protection and resources recovery: A systematic review on progress and perspectives. Membranes 2020, 10, 146.

10. Rogener, F.; Sartor, M.; Ban, A.; Buchloh, D.; Reichardt, T. Metal recovery from spent stainless steel pickling solution. Resour. Conserv. Recycl. 2012, 60, 72-77.

11. Wang, Y.; He, Y.; Yin, S.; Long, H.; Li, S. Research on extraction of zinc from spent pickling solution using Aliquat 336. Hydrometallurgy 2020, 93, 105322.

12. Randazzo, S.; Caruso, V.; Ciavardelli, D.; Micale, G.; Morreale, M. Recovery of zinc from spent pickling solutions by liquid-liquid extraction using TBP. Desalination Water Treat. 2019, 157, 110-117. [CrossRef]

13. Laso, J.; García, V.; Bringas, E.; Urtiaga, A.M.; Ortiz, I. Selective recovery of zinc over iron from spent pickling wastes by different membrane-based solvent extraction process configurations. Ind. Eng. Chem. Res. 2015, 54, 3218-3224. [CrossRef]

14. Khyati, S.; Kamalesh, G.; Bina, S. Selective separation of copper and zinc from spent chloride brass pickle liquors using solvent extraction and metal recovery by precipitation-stripping. J. Environ. Chem. Eng. 2017, 5, 5260-5269.

15. Verma, A.; Kore, R.; Corbin, D.R.; Shiflett, M.B. Metal recovery using oxalate chemistry: A technical review. Ind. Eng. Chem. Res. 2019, 58, 15381-15393. [CrossRef]

16. Lee, K.R.; Kim, J.; Jang, J.G. Recovery of zinc in spent pickling solution with oxalic acid. Korean J. Chem. Eng. 2017, 55, 785-790.

17. Stepanov, S.; Morozov, N.; Morozova, N.; Ayupov, D.; Makarov, D.; Baishev, D. Efficiency of use of galvanic sludge in cement systems. Procedia Eng. 2016, 165, 1112-1117. [CrossRef]

18. Becker, J.; Selbach, I.; Souza, J.; Brehm, F. Viability for the production of inorganic pigments from galvanic sludge. Int. Res. J. Adv. Eng. Tech. 2019, 5, 98-103. 
19. Felisberto, R.; Santos, M.C.; Arcaro, S.; Basegio, T.; Bergmann, C. Assessment of environmental compatibility of glass-ceramic materials obtained from galvanic sludge and soda-lime glass residue. Process Saf. Environ. 2018, 120, 72-78. [CrossRef]

20. Bednarik, V.; Vondruska, M.; Koutny, M. Stabilization/solidification of galvanic sludges by asphalt emulsions. J. Hazard. Mater. 2005, 122, 139-145. [CrossRef]

21. Filonov, A.V.; Kireeva, O.A. Prospects of galvanic sludge recycling. Appl. Mech. Mater. 2015, 770, 709-713. [CrossRef]

22. Krezel, A.; Maret, W. The biological inorganic chemistry of zinc ions. Arch. Biochem. Biophys. 2016, 611, 3-19. [CrossRef] [PubMed]

23. Decreto Legislativo Norme in materia ambientale. Valori limiti di emissioni in acque superficiali e in fognatura n. 152 del 2006. Available online: https:/ / www.gazzettaufficiale.it/dettaglio/codici/materiaAmbientale (accessed on 15 October 2020). 